\title{
IL-1ß promotes osteogenic differentiation of mouse bone marrow mesenchymal stem cells via the BMP/Smad pathway within a certain concentration range
}

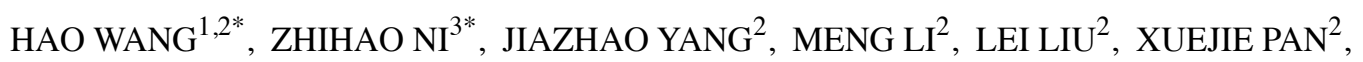 \\ LEI XU ${ }^{2}$, XUJIN WANG ${ }^{2}$ and SHIYUAN FANG ${ }^{2}$ \\ ${ }^{1}$ Department of Orthopedics, Huainan First People's Hospital, Anhui University of Science and Technology, \\ Huainan, Anhui 232000; ${ }^{2}$ Department of Orthopedics, Anhui Provincial Hospital, Anhui Medical University; \\ ${ }^{3}$ Department of Orthopedics, Hefei First People's Hospital, Anhui Medical University, Hefei, Anhui 230000, P.R. China
}

Received June 12, 2019; Accepted March 24, 2020

DOI: $10.3892 /$ etm.2020.9065

\begin{abstract}
Inflammatory factors play an important role in the process of fracture healing. The influence of interleukin (IL)-1 $\beta$, a key inflammatory factory, on new bone formation has been controversial. The aim of the present study was to investigate whether IL-1 $\beta$ affects the osteogenic differentiation of mouse bone marrow mesenchymal stem cells (MBMMSCs), and examined its effective concentration range and molecular mechanism of action. MBMMSC proliferation in the presence of IL-1 $\beta$ was observed using a Cell-Counting Kit- 8 assay, and the effect of IL-1 $\beta$ on MBMMSC apoptosis was examined via flow cytometry. Alkaline phosphatase assay, Alizarin Red staining and quantitative assays were performed to evaluate the osteogenic differentiation of MBMMSCs. The expression levels of osteogenic differentiation markers were detected using reverse transcription-quantitative PCR (RT-qPCR). It was demonstrated that within a concentration range of $0.01-1 \mathrm{ng} / \mathrm{ml}, \mathrm{IL}-1 \beta$ promoted osteogenic differentiation of MBMMSCs and did not induce apoptosis. Furthermore, RT-qPCR results indicated that IL-1 $\beta$ increased osteogenic gene expression within this concentration range. Moreover, Western blotting results identified that the bone morphogenetic protein/Smad (BMP/Smad)
\end{abstract}

Correspondence to: Dr Shiyuan Fang or Dr Xujin Wang, Department of Orthopedics, Anhui Provincial Hospital, Anhui Medical University, 17 Lujiang Road, Hefei, Anhui 230000, P.R. China

E-mail: fangshiyuan2008@126.com

E-mail:wxj680623@126.com

*Contributed equally

Abbreviations: IL-1 $\beta$, interleukin-1 $\beta$; ALP, alkaline phosphatase; MBMMSCs, mouse bone marrow mesenchymal stem cells; BMP, bone morphogenetic protein; OCN, osteocalcin; OPN, osteopontin; BSP, bone sialoprotein; RUNX2, runt-related transcription factor 2; COL1A1, type I collagen

Key words: osteogenesis, MBMMSCs,IL-1 $\beta$, BMP/Smad signaling pathway was significantly activated by IL-1 $\beta$ under osteogenic conditions. Therefore, the present results suggested that within a certain concentration range, IL-1 $\beta$ promoted osteogenic differentiation and function of MBMMSCs via the BMP/Smad signaling pathway.

\section{Introduction}

The fracture healing process involves many complex steps, and ultimately restores the structure and function of the fracture site $(1,2)$. The healing process begins immediately after a fracture occurs, and the local inflammatory reaction is a critical part of early healing (3). Moreover, the inflammatory response plays a vital role in the promotion and coordination of local osseous tissue regeneration (3). With the passive release of locally damaged tissue and the active release of inflammatory cells, the expression levels of inflammatory factors including tumor necrosis factor- $\alpha$ (TNF- $\alpha$ ), interleukin (IL)-1, IL-6, IL-11 and IL-18 are significantly elevated (4). Systemic and local release of these inflammatory factors have an important effect on biological processes such as vascular regeneration, cell recruitment and cartilaginous callus production (4).

Among these inflammatory factors, TNF- $\alpha$ and IL-1 have major functions in the regulation of fracture healing, and their secretion levels vary at different time points (4-6). These two master regulators of inflammation reach first peak levels between $24 \mathrm{~h}$ and 7 days after the fracture occurs (4-6). The process of cell recruitment into the hematoma is primarily activated by inflammatory factors at this stage $(5,6)$. Then, the expression levels of TNF- $\alpha$ and IL-1 decrease until the regulation of osseous tissue regeneration is required $(5,6)$. The second increase in these two regulators often occurs 4 weeks after fracture, and the specific time point and duration of this increase are related to the individual healing rate and age of the patient $(5,6)$.

Although direct fracture healing has been reported, indirect fracture healing is the main route of fracture healing (2,7). Both endochondral ossification and intramembranous ossification play important roles in indirect fracture healing, but intramembranous ossification is faster during 
bone regeneration (8-10). In order to form new osseous tissue that can resist rotational and shear forces, stem cells in the osteotylus differentiate into osteoblasts and bone cells, which then gradually mineralize (8-10). Mesenchymal stem cells (MSCs) can serve as both a source of bone-shaped osteoblasts and osteoprogenitor cells $(8,9)$, as well as having a paracrine effect on bone tissue regeneration (10). During the process of osseous tissue regeneration, the influence of inflammatory factors on osteogenic differentiation of bone marrow MSCs (BMMSCs) has been investigated (4). In inflammatory microenvironments, IL-1 and TNF- $\alpha$ have a prominent role in inflammatory osteolysis (11). While TNF- $\alpha$ has similar activity to that of IL- $1 \beta$, the expression of IL- $1 \beta$ is relatively higher in inflamed osseous tissues (12). As a major regulator of fracture healing, IL-1 $\beta$ reportedly promotes osteogenic differentiation of BMMSCs $(7,13,14)$. It has been shown that the use of non-steroidal anti-inflammatory drugs during the fracture healing phase leads to prolonged healing, which is consistent with the reported osteogenic effect of inflammatory factors (15-18). However, previous studies have revealed that IL-1 $\beta$ inhibits stem cell differentiation into osteoblasts, and this inhibitory effect is enhanced with increasing IL-1 $\beta$ concentration (19). In addition, the mechanism via which IL-1 $\beta$ affects osteogenic differentiation has been previously investigated, and the involvement of several signaling pathways has been identified (20-23). Bone morphogenetic protein/Smad (BMP/Smad) is a classical signaling pathway that is often activated during osteogenic differentiation of stem cells and plays a key role in early osteogenesis and late mineralization (24). However, whether the BMP/Smad signaling pathway participates in the effect of IL-1 $\beta$ on osteogenic differentiation is not fully understood $(19,25)$.

The aim of the present study was to investigate the effect on the osteogenic differentiation of mouse bone marrow mesenchymal stem cells (MBMMSCs) at various concentrations, in order to assess whether IL-1 $\beta$ has a positive effect on fracture healing. Using systematic experiments, the present study examined the maximum concentration of IL- $1 \beta$ that would be required to produce a positive effect, and identified the role of the BMP/Smad pathway after IL- $1 \beta$ stimulation.

\section{Materials and methods}

Cell culture. All animal experiments in this study were performed in accordance with the guidelines of Anhui Medical University, and were approved by the Ethics Committee at Anhui Medical University. In this experiment, five male C57BL/6 mice provided by the Anhui Laboratory Animal Center (age, 6 weeks; weight, 18-22 g) were used. Animals were housed at a temperature of $20-25^{\circ} \mathrm{C}, 50-60 \%$ humidity in a $12 / 12 \mathrm{~h}$ light/dark cycle and access to food and water. The main aim was to obtain primary cells (BMMSCs) from the mice. Euthanasia was performed by the inhalation of $\mathrm{CO}_{2}(100 \%)$ using a closed euthanasia device, which was placed in a ventilated environment. Before mice entered the device, low concentrations of $\mathrm{CO}_{2}$ were prepassed into the device. After mice entered the chamber, $100 \% \mathrm{CO}_{2}$ was gradually introduced. After determining the mortality of the mouse, $\mathrm{CO}_{2}(100 \%)$ was continually passed for $2 \mathrm{~min}$. If mice did not breathe spontaneously for $3 \mathrm{~min}$ and there was no blink reflex, mortality was confirmed. Primary MBMMSCs were isolated and expanded as previously described (26). Euthanized mice were sterilized in $70 \%$ ethanol for $15 \mathrm{~min}$, and cells were isolated from the femur and tibiae bone marrow, and then cultured in a T75 flask. To form complete medium, 10\% FBS (Gibco; Thermo Fisher Scientific, Inc.) and 1\% penicillin/streptomycin (Hyclone; GE Healthcare Life Sciences) were added to the $\alpha$ modification of Eagle's minimum essential medium (Hyclone; GE Healthcare Life Sciences). Primary cells were cultured in complete medium in an incubator containing $5 \% \mathrm{CO}_{2}$ at $37^{\circ} \mathrm{C}$ until the cells were fully confluent. The medium was changed every 3 days, and MBMMSCs at passage 3 were used in the subsequent experiments. MBMMSCs at passage 2 were identified by fluorescence activated cell sorting staining. Antibodies against CD90, CD105, CD34 and CD45 $(2 \mu \mathrm{g} / \mathrm{ml}$; BD Biosciences) were used for staining $\left(30 \mathrm{~min}\right.$ at $\left.25^{\circ} \mathrm{C}\right)$ and a flow cytometer (BD FACSCalibur; BD Biosciences) was used for the detection (Fig. S1).

Cell proliferation. The effect of IL-1 $\beta$ (R\&D Systems, Inc.) on the proliferation of MBMMSCs was detected using a Cell-Counting Kit-8 (CCK-8) assay (Dojindo Molecular Technologies, Inc.) according to the manufacturer's instructions. MBMMSCs $\left(5 \times 10^{3}\right.$ cells/well) were plated into 96 -well plates containing IL-1 $\beta$ at various concentrations $(0,0.01,0.1$, 1 or $10 \mathrm{ng} / \mathrm{ml}$ ) for 1,3 or 5 days at $37^{\circ} \mathrm{C}$. Cell culture medium was removed and $100 \mu 110 \% \mathrm{CCK}-8$ solution was added to each well. After $2 \mathrm{~h}$ of incubation at $37^{\circ} \mathrm{C}$, absorbance of the wells was measured at $450 \mathrm{~nm}$.

Cell apoptosis. The effect of IL-1 $\beta$ on MBMMSC apoptosis was assessed using flow cytometry via double-staining for Annexin V-FITC and PI (BD Biosciences). MBMMSCs were seeded into 24 -well plates $\left(8 \times 10^{4}\right.$ cells/well $)$ and collected $48 \mathrm{~h}$ after IL- $1 \beta$ treatment $(0,0.01,0.1,1$, or $10 \mathrm{ng} / \mathrm{ml})$ at $37^{\circ} \mathrm{C}$. Cells were washed twice with PBS and resuspended in $200 \mu \mathrm{l} 1 \mathrm{X}$ binding buffer (BD Biosciences) at a density of $5 \times 10^{5}$ cells $/ \mathrm{ml}$. Then, $5 \mu 1$ Annexin V-FITC and $10 \mu 1$ PI were added to the tube and incubated for $15 \mathrm{~min}$ in the dark at $25^{\circ} \mathrm{C}$. A flow cytometer (BD FACSCalibur; BD Biosciences) was used for the detection.

Assessment of alkaline phosphatase (ALP) activity and mineralized matrix formation. To assess the effect of IL-1 $\beta$ on osteogenic differentiation, MBMMSCs were seeded in 24 -well plates $\left(8 \times 10^{4}\right.$ cells/well). After the cells began to adhere to the plates, osteogenic medium (complete medium containing $10 \mathrm{mM} \beta$-glycerophosphate, $50 \mathrm{nM}$ ascorbic acid and $100 \mathrm{nM}$ dexamethasone; Sigma-Aldrich; Merck KGaA) containing IL- $1 \beta$ at different concentrations $(0,0.01,0.1,1$ or $10 \mathrm{ng} / \mathrm{ml}$ ) was added to induce differentiation.

For ALP staining, MBMMSCs were washed twice with PBS after 7 days of treatment. After fixing with $4 \%$ paraformaldehyde for $30 \mathrm{sec}$ at $25^{\circ} \mathrm{C}$, the cells were stained according to the manufacturer's instructions of the ALP staining kit (Beyotime Institute of Biotechnology). To quantitatively analyze ALP activity, MBMMSCs were washed twice with PBS and lysed with $1 \%$ Triton X-100 for 15 min. ALP activity was measured based on the absorbance at $405 \mathrm{~nm}$, and was normalized to total protein concentration using a bicinchoninic acid assay (Thermo Fisher Scientific, Inc.). 
Table I. Primer sequences for reverse transcription-quantitative PCR.

\begin{tabular}{lll}
\hline Gene & \multicolumn{1}{c}{ Forward $\left(5^{\prime}-3^{\prime}\right)$} & \multicolumn{1}{c}{ Reverse $\left(5^{\prime}-3^{\prime}\right)$} \\
\hline RUNX2 & GACTGTGGTTACCGTCATGGC & ACTTGGTTTTTCATAACAGCGGA \\
ALP & AGAAGTTCGCTATCTGCCTTGCCT & TGGCCAAAGGGCAATAACTAGGGA \\
COL1A1 & GCTCCTCTTAGGGGCCACT & CCACGTCTCACCATTGGGG \\
BSP & TGCTAACTGCGCAAACATACC & AGGGGGTGTGATAAAGGAACG \\
BMP2 & ACTACACGAAAGCAGTGGGAA & GCATCTGTTGCGAAACACT \\
OCN & TAGCAGACACCATGAGGACCATCT & CCTGCTTGGACATGAAGGCTTTGT \\
OPN & AGCAAGAAACTCTTCCAAGCAA & GTGAGATTCGTCAGATTCATCCG \\
GAPDH & AGGTCGGTGTGAACGGATTTG & TGTAGACCATGTAGTTGAGGTCA
\end{tabular}

ALP, alkaline phosphatase; BMP, bone morphogenetic protein; OCN, osteocalcin; OPN, osteopontin; BSP, bone sialoprotein; RUNX2, runt-related transcription factor 2; COL1A1, type I collagen.

In addition, MBMMSCs were stained with Alizarin Red (Wuhan Servicebio Technology Co., Ltd.) to assess mineralized matrix deposition for bone nodule formation after 21 days of IL-1 $\beta$ treatment. MBMMSCs were washed three times with PBS, fixed with $4 \%$ paraformaldehyde for $15 \mathrm{~min}$ at $25^{\circ} \mathrm{C}$ and stained with 1 Alizarin Red dye solution according to the manufacturer's instructions. For further quantitative analysis, a $10 \%$ chlorinated 16 alkyl pyridine solution of sodium phosphate ( $\mathrm{pH} 7.0$; Sigma-Aldrich; Merck KGaA) was added to dissolve the dye for $30 \mathrm{~min}$ at $25^{\circ} \mathrm{C}$, and the absorbance was measured at $620 \mathrm{~nm}$.

Reverse transcription-quantitative PCR (RT-qPCR). To determine the effect of IL- $1 \beta$ on downstream osteogenic genes during osteogenic induction, RT-qPCR was conducted to evaluate the relative expression of genes at different stages. Total RNA was extracted from MBMMSCs using TRIzol ${ }^{\mathbb{B}}$ reagent (Thermo Fisher Scientific, Inc.). All sample concentrations were normalized, and cDNA was synthesized using PrimeScript RT Master mix according to the manufacturer's instructions (Takara Bio, Inc.). qPCR was performed using SYBR ${ }^{\circledR}$ Premix EX Taq according to the manufacturer's instructions (Takara Bio, Inc.). The following thermocycling conditions were used for the qPCR: Initial denaturation at $95^{\circ} \mathrm{C}$ for $30 \mathrm{sec}$; followed by 40 cycles of $95^{\circ} \mathrm{C}$ for $5 \mathrm{sec}$ and $60^{\circ} \mathrm{C}$ for $30 \mathrm{sec}$. The primers used are shown in Table I. GAPDH was used as the internal reference gene for normalization. The $2^{-\Delta \Delta \mathrm{Cq}}$ method was used for quantification (27).

Western blot analysis. MBMMSCs in 6-well plates $\left(4 \times 10^{5}\right.$ cells/well) were lysed with RIPA buffer containing a protease inhibitor cocktail (Thermo Fisher Scientific, Inc.) and phenylmethylsulfonyl fluoride (Beyotime Institute of Biotechnology). The concentration of total protein was determined using a bicinchoninic acid assay. Equal amounts of protein $(20 \mu \mathrm{g} / \mathrm{lane})$ in each group were separated using $10 \%$ SDS-PAGE and transferred to PVDF membranes (EMD Millipore). After incubation in 5\% skimmed milk for $1 \mathrm{~h}$ at $25^{\circ} \mathrm{C}$ to block non-specific binding, the membranes were incubated with primary antibodies (1:1,000 dilution) against Smad1, Smad5, Smad4 and phosphorylated (p)-Smad1/5 (cat. no. 12656; Cell Signaling Technology, Inc.) and GAPDH (cat. no. 5174; Cell
Signaling Technology, Inc.) for $8 \mathrm{~h}$ at $4^{\circ} \mathrm{C}$. This was followed by incubation with horseradish peroxidase (HRP)-conjugated secondary antibody (1:2,000; cat. no. 7074; Cell Signaling Technology, Inc.) in Tris-buffered saline/ $0.1 \%$ Tween-20 at room temperature for $1 \mathrm{~h}$. The immunoreactive bands were visualized using Immobilon Western HRP (EMD Millipore). The Tanon 5200 chemiluminescent imaging system (Tanon Science and Technology Co., Ltd.) was used for densitometric analysis.

Treatment with signaling pathway inhibitor. To further evaluate the role of BMP/Smad signaling in osteogenic differentiation under IL-1 $\beta$ treatment, the BMP/Smad signaling pathway was blocked using LDN193189 (Selleck Chemicals). MBMMSCs were pre-stimulated with $0.2 \mu \mathrm{M}$ LDN193189 for $2 \mathrm{~h}$ at $37^{\circ} \mathrm{C}$ and then stimulated with $0.1 \mathrm{ng} / \mathrm{ml} \mathrm{IL}-1 \beta$ at $37^{\circ} \mathrm{C}$ until the time of detection (Western blot analysis at 7 days, ALP analysis at 7 days, mineralization analysis at 21 days and qPCR analysis at 7 days).

Statistical analysis. Data are presented as the mean \pm SD from $\geq 3$ independent experiments. The results were analyzed by one-way ANOVA using SPSS 23.0 software (IBM Corp.). Dunnett's multiple comparisons test was used as the post-hoc test. $\mathrm{P}<0.05$ was considered to indicate a statistically significant difference.

\section{Results}

Effect of IL-1 $\beta$ on MBMMSC proliferation and apoptosis. Prior to investigating the effect of IL-1 $\beta$ on osteogenic differentiation, it was important to determine whether it affects the proliferation of MBMMSCs. It was found that MBMMSCs treated with various concentrations of IL-1 $\beta$ maintained similar proliferation rates compared with the control group (Fig. 1A). Moreover, it was demonstrated that IL- $1 \beta$ did not induce cytotoxicity to MBMMSCs at the highest concentration $(20 \mathrm{ng} / \mathrm{ml})$. In addition, the present results suggested that IL-1 $\beta$ at different concentrations did not cause significant early apoptosis of MBMMSCs (Fig. 1B).

IL-1 $\beta$ enhances osteogenic differentiation of MBMMSCs within a certain concentration range. To assess the influence of 


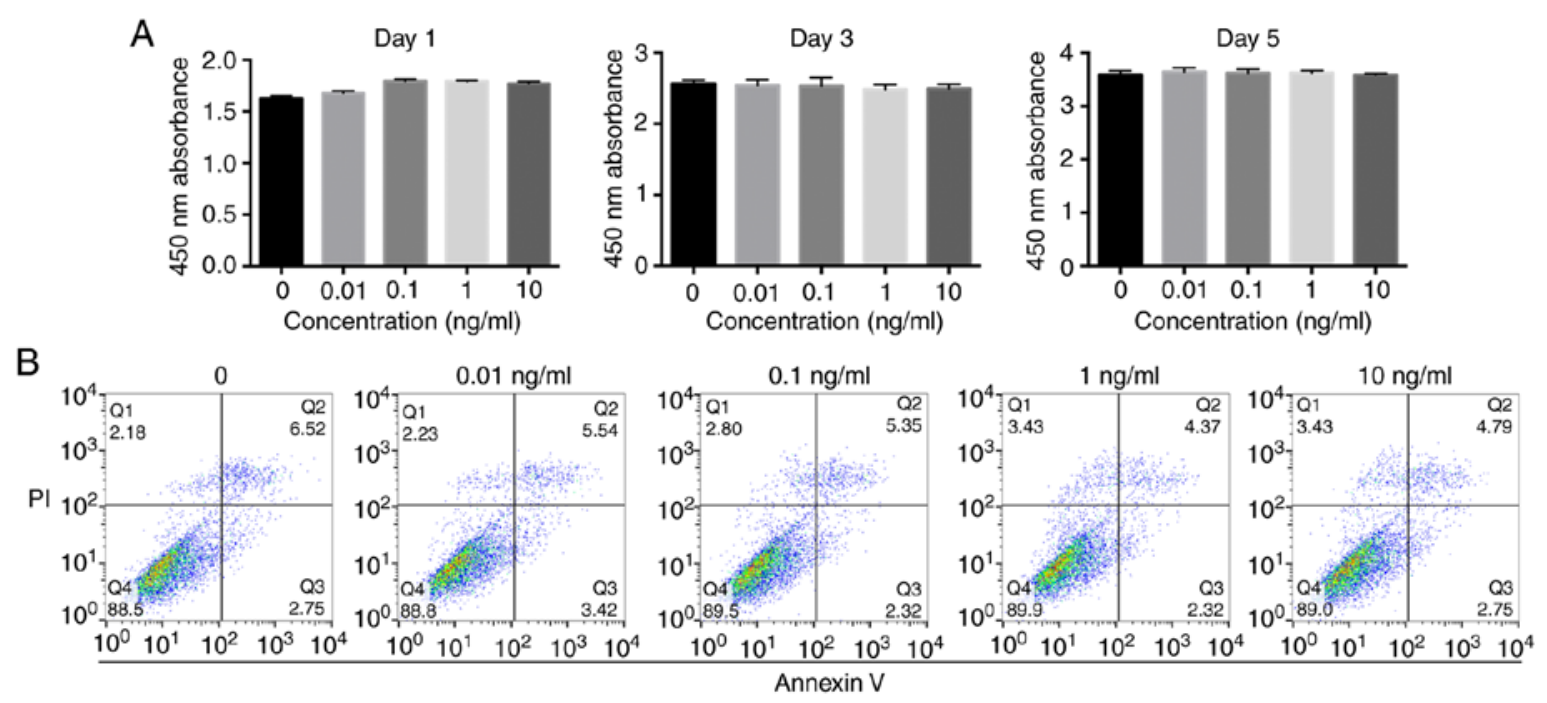

Figure 1. Effects of IL-1 $\beta$ on viability of MBMMSCs. (A) MBMMSCs were treated with different concentrations of IL-1 $1 \beta$ for 1,3 and 5 days prior to measuring cell proliferation with a Cell Counting Kit-8 assay. (B) Cell apoptosis was assessed by flow cytometry after $48 \mathrm{~h}$ incubation with different concentrations of IL-1 1 . IL, interleukin; MBMMSCs, mouse bone marrow mesenchymal stem cells.

IL-1 $\beta$ on osteogenic differentiation of MBMMSCs, ALP assay, Alizarin Red staining and quantitative tests were performed. It was demonstrated that IL-1 $\beta$ caused osteogenic differentiation at very low concentrations ( $0.01 \mathrm{ng} / \mathrm{ml}$; Fig. $2 \mathrm{~A})$. Furthermore, with increasing IL-1 $\beta$ concentration, the osteogenic effect of IL-1 $\beta$ was increased, and similar results were obtained at 0.1 and $1 \mathrm{ng} / \mathrm{ml}$. When the IL- $1 \beta$ concentration continued to increase, its osteogenic effect on MBMMSCs began to decrease, and showed a relative inhibitory effect at $10 \mathrm{ng} / \mathrm{ml}$. Moreover, quantitative analysis results were similar (Fig. 2B), thus indicating that IL- $1 \beta$ promoted the osteogenic differentiation of MBMMSCs within a certain range, but this effect disappeared after exceeding this range.

$I L-1 \beta$ upregulates the expression of osteogenic genes. The transcriptional level of the osteogenic genes is altered after activation of various signaling pathways $(24,28,29)$. Therefore, the mRNA expression levels of the downstream osteogenic differentiation markers Runx2, ALP, collagen 1A1 (COL1A1), bone sialoprotein (BSP), BMP2, osteocalcin (OCN) and osteopontin (OPN), were determined using RT-qPCR. It was found that Runx 2 mRNA expression was increased after 3 days of IL-1 $\beta$ treatment. On day 7, the mRNA expression levels of ALP, COL1A1, BSP and BMP2 in the IL-1 $\beta$-treated MBMMSCs were significantly increased compared with the control group, and the mRNA expression levels of OCN and OPN began to increase. By day 14, the expression levels of OCN and OPN were found to further increase. Similar to osteogenic differentiation, the expression of osteogenic genes in MBMMSCs did not increase after stimulation with $10 \mathrm{ng} / \mathrm{ml}$ IL-1 $\beta$, and the overall expression levels were lower compared with the control group (Fig. 3). Therefore, the present results suggested that IL-1 $\beta$ may regulate osteogenic differentiation at the mRNA level.

Activation of the BMP/Smad signaling pathway in MBMMSCs. To assess whether the BMP/Smad classical osteogenic pathway is involved in the effect of IL-1 $\beta$ on the osteogenic differentiation of MBMMSCs, the activation of Smad signaling was examined by Western blot analysis during osteogenesis. It was demonstrated that the phosphorylation of Smad1/5, which represents the activation level of the BMP/Smad pathway $(30,31)$, was significantly increased after 7 days of IL-1 $\beta$ stimulation (Fig. 4A and B). However, the protein expression levels of Smad1, Smad4 and Smad5 were unchanged after IL-1 $\beta$ treatment (Fig. 4). Moreover, the phosphorylation level of Smad1/5 showed a downward trend at $10 \mathrm{ng} / \mathrm{ml} \mathrm{IL-1} \beta$. Thus, the present results indicated that IL-1 $\beta$ regulated osteogenic differentiation of MBMMSCs via the $\mathrm{BMP} /$ Smad signaling pathway.

Inhibition of the BMP/Smad signaling pathway suppresses $I L-1 \beta$-induced osteogenic differentiation. LDN193189 is a transforming growth factor (TGF) $-\beta /$ Smad inhibitor that is often used to inhibit BMP2-induced p-Smad1/5/9 (32-34). Western blot analysis was performed to evaluate Smad phosphorylation levels after 7 days. It was identified that LDN193189 significantly reduced the protein expression level of p-Smad $1 / 5$ stimulated by $0.1 \mathrm{ng} / \mathrm{ml}$ IL- $1 \beta$, returning to levels similar to the control group (Fig. 5). It was also found that blocking the BMP/Smad signaling pathway decreased ALP and mineralization staining, and similar results were obtained from the quantitative assays (Fig. 5C and D). Moreover, these results were further supported by the results of the RT-qPCR (Fig. 5E). Collectively, the present results suggested that the BMP/Smad signaling pathway may have an important role in IL-1 $\beta$-induced osteogenic differentiation.

\section{Discussion}

The present study investigated the role of IL- $1 \beta$ in osteogenic differentiation during fracture healing and assessed the conditions under which IL- $1 \beta$ exerted a positive effect on MBMMSCs. Several controversial issues, which had been highlighted in previous studies, were addressed by the 

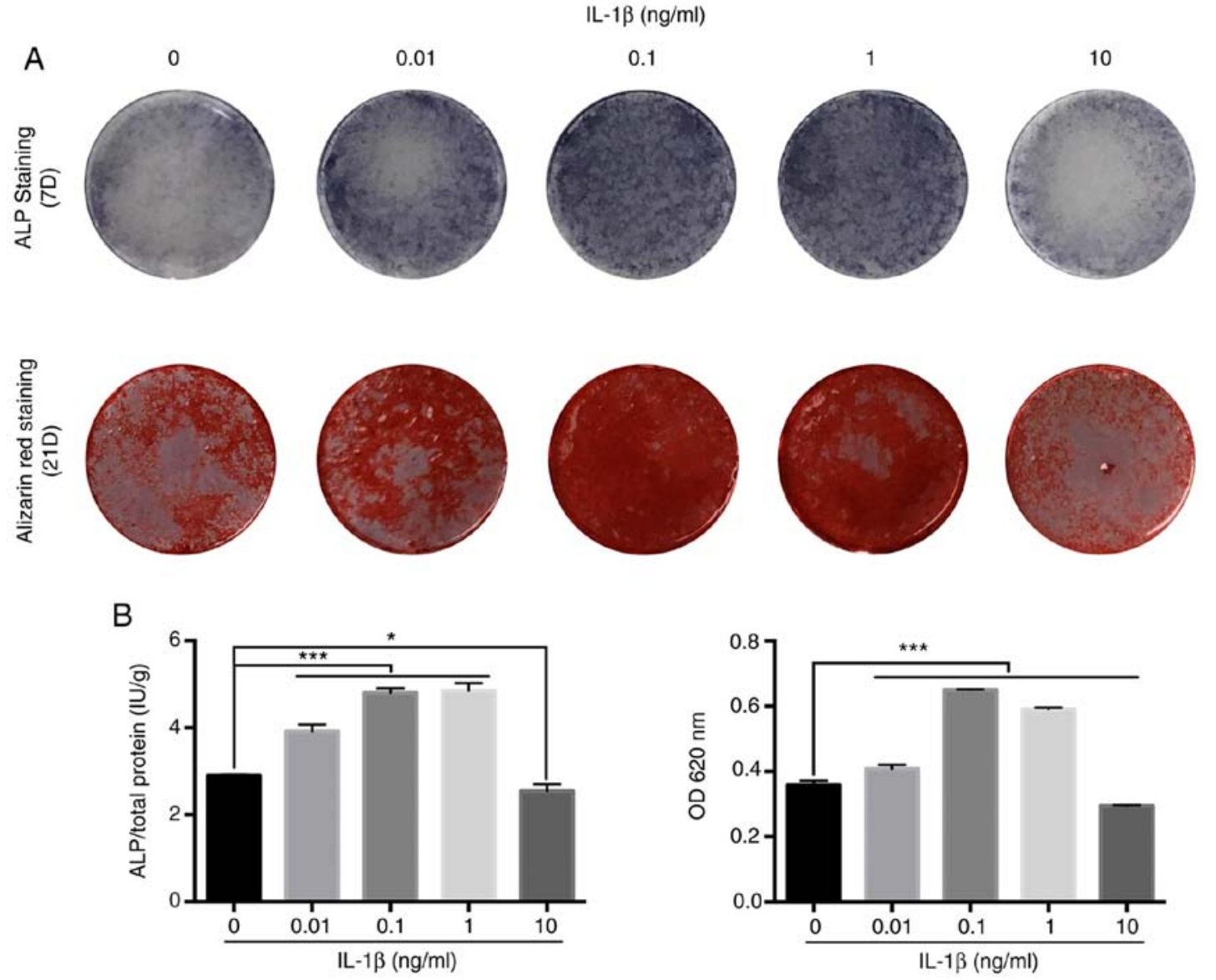

Figure 2. Effect of IL-1 $\beta$ on osteogenic differentiation of mouse bone marrow mesenchymal stem cells. (A) Whole plate views of ALP staining at 7 days and alizarin red staining at 21 days. (B) Quantitative evaluation of ALP activity and alizarin red staining. ${ }^{*} \mathrm{P}<0.05,{ }^{* * * *} \mathrm{P}<0.001$. IL, interleukin; ALP, alkaline phosphatase.
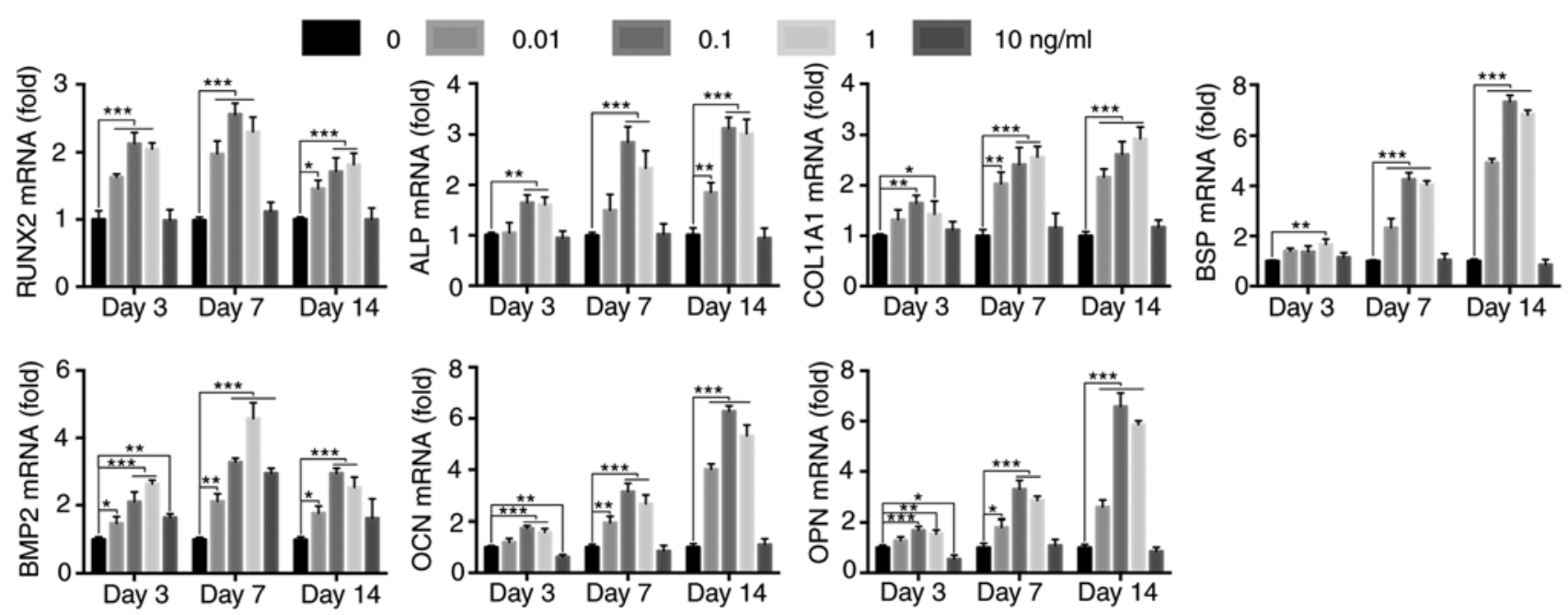

Figure 3. Effect of IL-1 $\beta$ on downstream osteogenic genes. mRNA expression levels of RUNX2, ALP, COL1A1, BSP, BMP2, OCN and OPN at 3, 7 and 14 days. Expression levels were normalized to GAPDH. ${ }^{*} \mathrm{P}<0.05,{ }^{* *} \mathrm{P}<0.01,{ }^{* * * *} \mathrm{P}<0.001$. IL, interleukin; ALP, alkaline phosphatase; BMP, bone morphogenetic protein; OCN, osteocalcin; OPN, osteopontin; BSP, bone sialoprotein; RUNX2, runt-related transcription factor 2; COL1A1, type I collagen.

present results $(14,19,35)$. Firstly, it was found that IL-1 $\beta$ did not promote the proliferation of MBMMSCs, or induce cytotoxicity and apoptosis within a certain concentration range. Furthermore, IL-1 $\beta$ positively regulated the osteogenic differentiation of MBMMSCs within a certain concentration range, and when the concentration was too high, osteogenic differentiation did not occur and was inhibited. Moreover, it was demonstrated that the BMP/Smad signaling pathway was activated in IL-1 $\beta$-mediated osteogenic regulation.

Prior to investigating the effect of IL-1 $\beta$ on osteogenic differentiation, the present study first assessed its effect on MBMMSC proliferation and apoptosis. It was demonstrated 
A

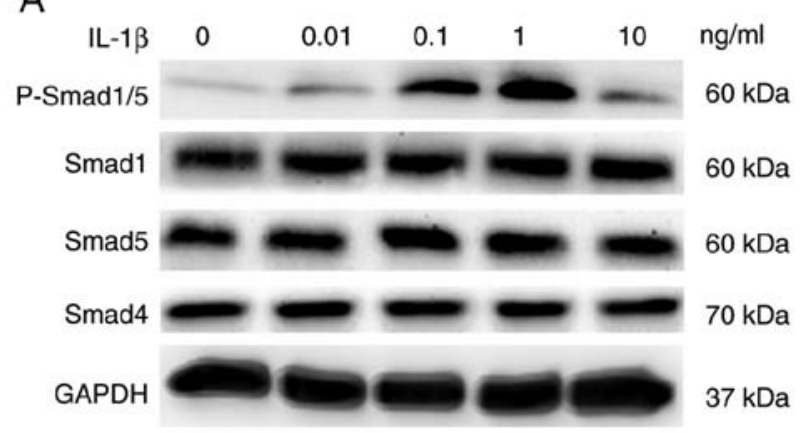

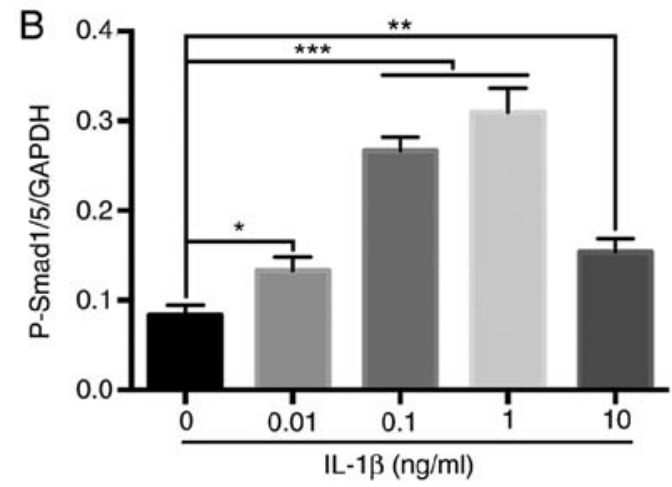

Figure 4. Effect of IL-1 $\beta$ on the BMP/Smad signaling pathway in mouse bone marrow mesenchymal stem cells. (A) Levels of p-Smad1/5, overall Smad1, Smad5 and Smad4 at 7 days were examined via Western blot analysis. (B) Quantitative assay of p-Smad1/5/GAPDH. ${ }^{*} \mathrm{P}<0.05,{ }^{* *} \mathrm{P}<0.01,{ }^{* * *} \mathrm{P}<0.001$. p-, phosphorylated; IL, interleukin; BMP, bone morphogenetic protein.

A

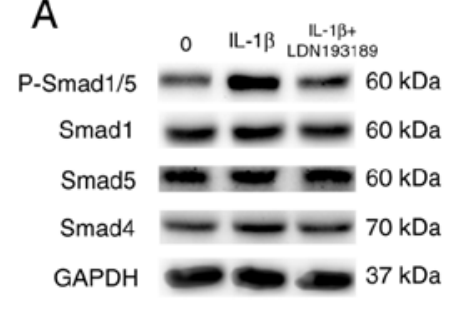

$\mathrm{B}$

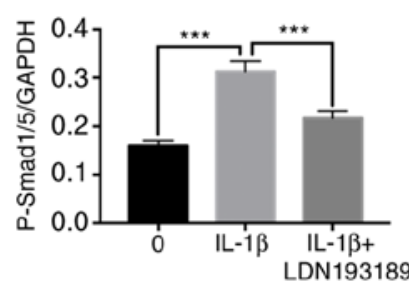

C

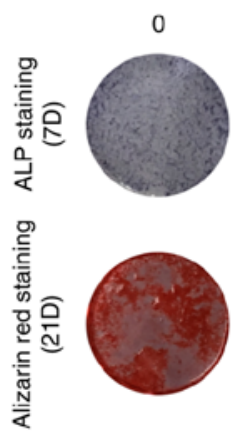

$\mathrm{IL}-1 \beta$

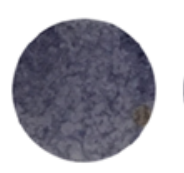
LDN193189
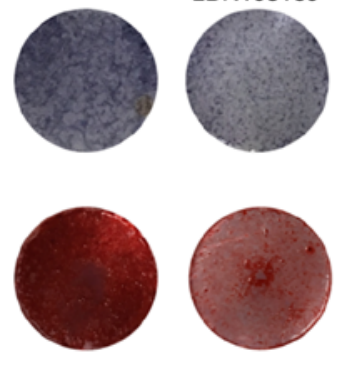

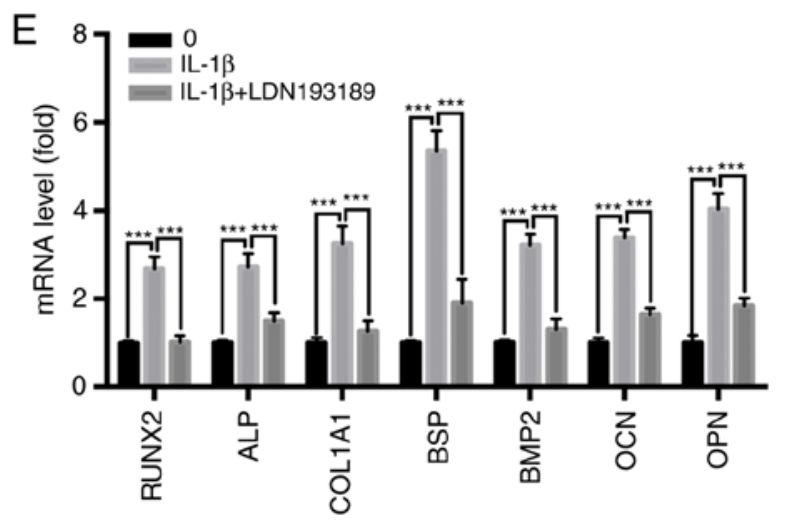

$\mathrm{D}$
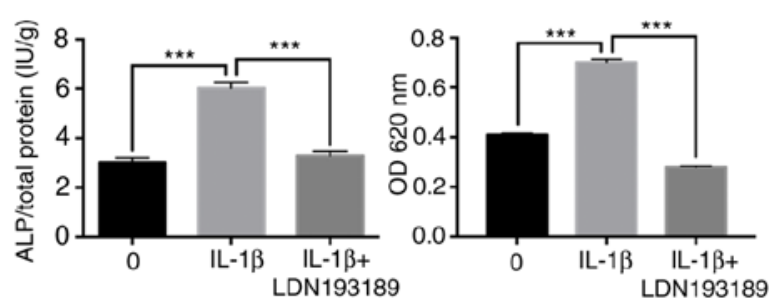

Figure 5. Effect of TGF- $\beta /$ Smad inhibitor on the osteogenic differentiation of MBMMSCs. MBMMSCs were treated with osteogenic differentiation medium in the presence of $0.1 \mathrm{ng} / \mathrm{ml} \mathrm{IL-1 \beta}$ along with the inhibitor of TGF- $\beta /$ Smad LDN193189. (A) Western blot analysis results for the levels of p-Smad1/5, and total Smad1, Smad5 and Smad4 at 7 days. (B) Quantitative results of p-Smad1/5/GAPDH. (C) Entire plate views of ALP staining at 7 days and alizarin red staining at 21 days. (D) Quantitative evaluation of ALP activity and alizarin red staining results. (E) mRNAs expression levels of RUNX2, ALP, COL1A1, BSP, BMP2, OCN and OPN at 7 days. Expression levels were normalized to GAPDH. ${ }^{* * *} \mathrm{P}<0.001$. p-, phosphorylated; IL, interleukin; ALP, alkaline phosphatase; BMP, bone morphogenetic protein; OCN, osteocalcin; OPN, osteopontin; BSP, bone sialoprotein; RUNX2, runt-related transcription factor 2; COL1A1, type I collagen; MBMMSCs, mouse bone marrow mesenchymal stem cells.

that IL-1 $\beta$ concentrations within a certain range did not significantly promote or inhibit the proliferation of MBMMSCs, which eliminated interference in the subsequent osteogenic differentiation experiments. Moreover, previously reported concentrations of IL-1 $\beta$, which are shown to contribute to osteogenic differentiation of various cells, are within this selected range $(7,14,19,25)$. In addition, as early cell apoptosis cannot pass endpoint monitoring methods such as CCK-8 (26), the present study examined whether IL-1 $\beta$ induced cell membrane damage in MBMMSCs by evaluating Annexin V on the cell membrane surface. The present results suggested that IL-1 $\beta$ stimulation did not induce significant early apoptosis in MBMMSCs, thus establishing the basis for subsequent experiments.
During the process of fracture healing, the sterile inflammatory response plays an important role at all stages (4-6). A variety of inflammatory factors act as executors of inflammatory response, exerting a variety of regulatory functions in fracture healing (4-6). Among them, the regulation of IL-1 $\beta$ on new bone formation has been extensively studies; however, there are discrepancies between these results $(6,7,14)$. The main reasons for these inconsistencies may include unclear concentration ranges and differentiation of experimentally selected cells. The present study selected BMMSCs, which is an important source of new osseous tissue, to assess the regulatory role of IL-1 $\beta$ in osteogenic differentiation within a sufficiently large concentration range. The present results suggested that the addition of IL- $1 \beta$ at $0.01-1 \mathrm{ng} / \mathrm{ml}$ under 
osteogenic induction significantly enhanced the osteogenic differentiation of MBMMSCs, and this was demonstrated by the mRNA expression levels of downstream osteogenic genes. Unlike IL-1 $\beta$, other inflammatory factors such as TNF- $\alpha$ do not cause similar osteogenic promoting effects (36-39). Previous findings have shown that TNF- $\alpha$ significantly inhibits osteogenic differentiation potential of MSCs at different concentrations (36-39). In the present study, when IL-1 $\beta$ concentration was increased to $10 \mathrm{ng} / \mathrm{ml}$, osteogenic promotion disappeared and osteogenic genes were downregulated. Thus, the present results indicated that IL-1 $\beta$ promoted new bone formation during fracture healing only within a specific concentration range. Furthermore, excess IL-1 $\beta$ may not be beneficial to fracture healing and may produce adverse results. From the overall perspective of the fracture healing process, the aseptic inflammatory response is essential, but excessive inflammation hinders fracture healing (4-6). Therefore, further animal experiments are required to investigate the effect of IL-1 $\beta$ on fracture healing in vivo. In an animal model, IL-1 $\beta$ could be loaded onto the surface of implants by internal fixation and surface modification to reach a stable local IL-1 $\beta$ concentration at the fracture site (40).

Multiple signaling pathways are involved in regulating the osteogenic differentiation of BMMSCs, such as the Wnt/ $\beta$-catenin (20), mitogen-activated protein kinase (21), phosphoinositide 3-kinase (22) and estrogen receptor pathways (23). BMP/Smad, one of the classical osteogenic signaling pathways, has been reported to participate in IL- $1 \beta$-induced differentiation of periodontal cells (19). However, it has also been reported that the BMP/Smad signaling pathway is not involved in the regulation of the differentiation potential of BMMSCs by IL-1 $\beta$ (25). If IL-1 $\beta$ acts via the BMP/Smad pathway, signaling will be initiated with ligand-induced oligomerization of serine/threonine receptor kinases and phosphorylation of the cytoplasmic signaling molecules Smad1/5/9 (19,30,31). Furthermore, carboxy-terminal phosphorylation of Smads by activated receptors results in their binding with the common signaling transducer Smad4, and causes their translocation to the nucleus $(30,31)$. In the present study p-Smad1/5, which shares the same binding site as p-Smad1/5/9 (30,31), was used as an indication of BMP/Smad activation. To further demonstrate that IL-1 $\beta$ regulated osteogenic differentiation of MBMMSCs via the BMP/Smad signaling pathway, a TGF- $\beta /$ Smad inhibitor was used to block the activity of this pathway. The impaired osteogenic effect identified in suggested that the BMP/Smad pathway may play a vital role in the regulation of MBMMSC osteogenic differentiation by IL-1 $\beta$.

However, there are several limitations to the present study that require discussion. Firstly, MBMMSCs were selected as the research subject, however to obtain results that are clinically application the use of human cells may be more beneficial. Therefore, future experiments will use human BMMSCs. Furthermore, the intensity of BMP/Smad activation stimulated by IL-1 $\beta$ at different concentrations may not completely correspond to the observed osteogenic effects. When the IL-1 $\beta$ concentration $>1 \mathrm{ng} / \mathrm{ml}$, its osteogenic effect was reduced, but the expression level of $\mathrm{p}-\mathrm{Smad} 1 / 5$ was still relatively high. Thus, the present results suggested that other signaling pathways may be activated and participate in the regulation of osteogenic differentiation by IL-1 $\beta$, and this requires further investigation.

In conclusion, the present results indicated that IL-1 $\beta$ enhanced the osteogenic differentiation potential of MBMMSCs within a certain concentration range. It was also demonstrated that IL-1 $\beta$ activated the classical BMP/Smad osteogenic signaling pathway and its osteogenic induction effect was lost when the concentration was too high. Therefore, the present results suggested that regulation of the BMP/Smad signaling pathway by IL-1 $\beta$ may be a novel therapeutic for the treatment of fracture healing.

\section{Acknowledgements}

Not applicable.

\section{Funding}

No funding was received.

\section{Availability of data and materials}

The datasets used and/or analyzed during the current study are available from the corresponding author on reasonable request.

\section{Authors' contributions}

HW, ZN, JY, ML, LL, XP, LX and XW carried out the experiments. HW wrote the manuscript. SF and XW designed the experiments. SF revised the manuscript. All authors read and approved the final manuscript.

\section{Ethics approval and consent to participate}

All animal experiments in the present study were performed in accordance with the Laboratory Animal Management Regulations, and were approved by the Ethics Committee at Anhui Provincial Hospital, Anhui Medical University

\section{Patient consent for publication}

Not applicable.

\section{Competing interests}

The authors declare that they have no competing interests.

\section{References}

1. Behonick DJ, Xing Z, Lieu S, Buckley JM, Lotz JC, Marcucio RS Werb Z, Miclau T and Colnot C: Role of matrix metalloproteinase 13 in both endochondral and intramembranous ossification during skeletal regeneration. PLoS One 2: e1150, 2007.

2. Marsell R and Einhorn TA: The biology of fracture healing. Injury 42: 551-555, 2011.

3. Loi F, Córdova LA, Pajarinen J, Lin TH, Yao Z and Goodman SB: Inflammation, fracture and bone repair. Bone 86: 119-130, 2016.

4. Gerstenfeld LC, Cullinane DM, Barnes GL, Graves DT and Einhorn TA: Fracture healing as a post-natal developmental process: Molecular, spatial, and temporal aspects of its regulation. J Cell Biochem 88: 873-884, 2003. 
5. Cho TJ, Gerstenfeld LC and Einhorn TA: Differential temporal expression of members of the transforming growth factor beta superfamily during murine fracture healing. J Bone Miner Res 17: 513-520, 2002.

6. Lange J, Sapozhnikova A, Lu C, Hu D, Li X, Miclau T III and Marcucio RS: Action of IL-1beta during fracture healing. J Orthop Res 28: 778-784, 2010.

7. Mumme M, Scotti C, Papadimitropoulos A, Todorov A, Hoffmann W, Bocelli-Tyndall C, Jakob M, Wendt D, Martin I and Barbero A: Interleukin- $1 \beta$ modulates endochondral ossification by human adult bone marrow stromal cells. Eur Cell Mater 24 224-236, 2012

8. Bielby RC, Boccaccini AR, Polak JM and Buttery LD: In vitro differentiation and in vivo mineralization of osteogenic cells derived from human embryonic stem cells. Tissue Eng 10: $1518-1525,2004$.

9. Sottile V, Thomson A and McWhir J: In vitro osteogenic differentiation of human ES cells. Cloning Stem Cells 5: 149-155, 2003

10. Furuta T, Miyaki S, Ishitobi H, Ogura T, Kato Y, Kamei N, Miyado K, Higashi $\mathrm{Y}$ and Ochi M: Mesenchymal stem cell-derived exosomes promote fracture healing in a mouse model. Stem Cells Transl Med 5: 1620-1630, 2016.

11. Graves DT and Cochran D: The contribution of interleukin-1 and tumor necrosis factor to periodontal tissue destruction. J Periodontol 74: 391-401, 2003.

12. Stashenko P, Jandinski JJ, Fujiyoshi P, Rynar J and Socransky SS Tissue levels of bone resorptive cytokines in periodontal disease. J Periodontol 62: 504-509, 1991.

13. Loebel C, Czekanska EM, Staudacher J, Salzmann G Richards RG, Alini M and Stoddart MJ: The calcification potential of human MSCs can be enhanced by interleukin- $1 \beta$ in osteogenic medium. J Tissue Eng Regen Med 11: 564-571, 2017.

14. Sonomoto K, Yamaoka K, Oshita K, Fukuyo S, Zhang X, Nakano K, Okada Y and Tanaka Y: Interleukin-1 $\beta$ induces differentiation of human mesenchymal stem cells into osteoblasts via the Wnt-5a/receptor tyrosine kinase-like orphan receptor 2 pathway. Arthritis Rheum 64: 3355-3363, 2012.

15. Bhattacharyya T, Levin R, Vrahas MS and Solomon DH: Nonsteroidal antiinflammatory drugs and nonunion of humeral shaft fractures. Arthritis Rheum 53: 364-367, 2005.

16. O'Connor JP, Capo JT, Tan V, Cottrell JA, Manigrasso MB Bontempo N and Parsons JR: A comparison of the effects of ibuprofen and rofecoxib on rabbit fibula osteotomy healing. Acta Orthop 80: 597-605, 2009.

17. Burd TA, Hughes MS and Anglen JO: Heterotopic ossification prophylaxis with indomethacin increases the risk of long-bone nonunion. J Bone Joint Surg Br 85: 700-705, 2003.

18. Krischak GD, Augat P, Sorg T, Blakytny R, Kinzl L, Claes L and Beck A: Effects of diclofenac on periosteal callus maturation in osteotomy healing in an animal model. Arch Orthop Trauma Surg 127: 3-9, 2007

19. Mao CY, Wang YG, Zhang X, Zheng XY, Tang TT and Lu EY: Double-edged-sword effect of IL-1 $\beta$ on the osteogenesis of periodontal ligament stem cells via crosstalk between the NF- $\mathrm{BB}$ MAPK and BMP/Smad signaling pathways. Cell Death Dis 7: e2296, 2016.

20. Saidak Z, Le Henaff C, Azzi S, Marty C, Da Nascimento S, Sonnet $\mathrm{P}$ and Marie PJ: Wnt/ $\beta$-catenin signaling mediates osteoblast differentiation triggered by peptide-induced $\alpha 5 \beta 1$ integrin priming in mesenchymal skeletal cells. J Biol Chem 290 6903-6912, 2015.

21. Thouverey $\mathrm{C}$ and Caverzasio J: Focus on the p 38 MAPK signaling pathway in bone development and maintenance. Bonekey Rep 4 $711,2015$.

22. Guntur AR and Rosen CJ: The skeleton: a multi-functional complex organ: New insights into osteoblasts and their role in bone formation: The central role of PI3Kinase. J Endocrinol 211: 123-130, 2011

23. Vico L and Vanacker JM: Sex hormones and their receptors in bone homeostasis: Insights from genetically modified mouse models. Osteoporos Int 21: 365-372, 2010.
24. Lee KW, Yook JY, Son MY, Kim MJ, Koo DB, Han YM and Cho YS: Rapamycin promotes the osteoblastic differentiation of human embryonic stem cells by blocking the mTOR pathway and stimulating the BMP/Smad pathway. Stem Cells Dev 19: 557-568, 2010.

25. Ye W, Fei XM, Tang Y, Xu XX and Zhu Y: IL-1 $\beta$-treated bone marrow mesenchymal stem cells enhances osteogenetic potential via NF-кB pathway. Zhongguo Shi Yan Xue Ye Xue Za Zhi 25: 890-895, 2017 (In Chinese)

26. Liu X, Qu X, Wu C, Zhai Z, Tian B, Li H, Ouyang Z, Xu X, Wang W, Fan Q, et al: The effect of enoxacin on osteoclastogenesis and reduction of titanium particle-induced osteolysis via suppression of JNK signaling pathway. Biomaterials 35: 5721-5730, 2014

27. Livak KJ and Schmittgen TD: Analysis of relative gene expression data using real-time quantitative PCR and the 2(-Delta Delta $\mathrm{C}(\mathrm{T})$ ) method. Methods 25: 402-408, 2001.

28. Wu M, Chen G and Li YP: TGF- $\beta$ and BMP signaling in osteoblast, skeletal development, and bone formation, homeostasis and disease. Bone Res 4: 16009, 2016.

29. Wang YJ, Zhang HQ, Han HL, Zou YY, Gao QL and Yang GT: Taxifolin enhances osteogenic differentiation of human bone marrow mesenchymal stem cells partially via NF- $\kappa \mathrm{B}$ pathway. Biochem Biophys Res Commun 490: 36-43, 2017.

30. Schmierer B and Hill CS: TGFbeta-SMAD signal transduction: Molecular specificity and functional flexibility. Nat Rev Mol Cell Biol 8: 970-982, 2007.

31. Xiao YT, Xiang LX and Shao JZ: Bone morphogenetic protein Biochem Biophys Res Commun 362: 550-553, 2007.

32. Ying X, Sun L, Chen X, Xu H, Guo X, Chen H, Hong J, Cheng S and Peng L: Silibinin promotes osteoblast differentiation of human bone marrow stromal cells via bone morphogenetic protein signaling. Eur J Pharmacol 721: 225-230, 2013.

33. Peart TM, Correa RJ, Valdes YR, Dimattia GE and Shepherd TG: BMP signalling controls the malignant potential of ascites-derived human epithelial ovarian cancer spheroids via AKT kinase activation. Clin Exp Metastasis 29: 293-313, 2012.

34. Vogt J, Traynor R and Sapkota GP: The specificities of small molecule inhibitors of the TGF $\beta$ and BMP pathways. Cell Signal 23: 1831-1842, 2011.

35. Huang RL, Yuan Y, Tu J, Zou GM and Li Q: Opposing TNF- $\alpha /$ IL-1 $\beta$ - and BMP-2-activated MAPK signaling pathways converge on Runx2 to regulate BMP-2-induced osteoblastic differentiation. Cell Death Dis 5: e1187, 2014.

36. Qiu X, Wang X, Qiu J, Zhu Y, Liang T, Gao B, Wu Z, Lian C, Peng Y, Liang A, et al: Melatonin rescued reactive oxygen species-impaired osteogenesis of human bone marrow mesenchymal stem cells in the presence of tumor necrosis factor-alpha. Stem Cells Int 2019: 6403967, 2019.

37. Wang X, Sun H, Liao H, Wang C, Jiang C, Zhang Y and Cao Z: MicroRNA-155-3p mediates TNF- $\alpha$-inhibited cementoblast differentiation. J Dent Res 96: 1430-1437, 2017.

38. Chang J, Liu F, Lee M, Wu B, Ting K, Zara JN, Soo C, Al Hezaimi K, Zou W, Chen X, et al: NF- $\mathrm{kB}$ inhibits osteogenic differentiation of mesenchymal stem cells by promoting $\beta$-catenin degradation. Proc Natl Acad Sci USA 110: 9469-9474, 2013.

39. Yang N, Wang G, Hu C, Shi Y, Liao L, Shi S, Cai Y, Cheng S, Wang X, Liu Y, et al: Tumor necrosis factor $\alpha$ suppresses the mesenchymal stem cell osteogenesis promoter miR-21 in estrogen deficiency-induced osteoporosis. J Bone Miner Res 28: 559-573, 2013.

40. Zhang BG, Myers DE, Wallace GG, Brandt M and Choong PF: Bioactive coatings for orthopaedic implants-recent trends in development of implant coatings. Int J Mol Sci 15: 11878-11921, 2014.

This work is licensed under a Creative Commons Attribution-NonCommercial-NoDerivatives 4.0 International (CC BY-NC-ND 4.0) License. 